\title{
Health in South Africa: changes and challenges since 2009
}

\author{
Bongani M Mayosi, Joy E Lawn, Ashley van Niekerk, Debbie Bradshaw, Salim S Abdool Karim, Hoosen M Coovadia, for The Lancet South Africa team
}

Since the 2009 Lancet Health in South Africa Series, important changes have occurred in the country, resulting in an increase in life expectancy to 60 years. Historical injustices together with the disastrous health policies of the previous administration are being transformed. The change in leadership of the Ministry of Health has been key, but new momentum is inhibited by stasis within the health management bureaucracy. Specific policy and programme changes are evident for all four of the so-called colliding epidemics: HIV and tuberculosis; chronic illness and mental health; injury and violence; and maternal, neonatal, and child health. South Africa now has the world's largest programme of antiretroviral therapy, and some advances have been made in implementation of new tuberculosis diagnostics and treatment scale-up and integration. HIV prevention has received increased attention. Child mortality has benefited from progress in addressing HIV. However, more attention to postnatal feeding support is needed. Many risk factors for non-communicable diseases have increased substantially during the past two decades, but an ambitious government policy to address lifestyle risks such as consumption of salt and alcohol provide real potential for change. Although mortality due to injuries seems to be decreasing, high levels of interpersonal violence and accidents persist. An integrated strategic framework for prevention of injury and violence is in progress but its successful implementation will need high-level commitment, support for evidence-led prevention interventions, investment in surveillance systems and research, and improved human-resources and management capacities. A radical system of national health insurance and re-engineering of primary health care will be phased in for 14 years to enable universal, equitable, and affordable health-care coverage. Finally, national consensus has been reached about seven priorities for health research with a commitment to increase the health research budget to $2 \cdot 0 \%$ of national health spending. However, large racial differentials exist in social determinants of health, especially housing and sanitation for the poor and inequity between the sexes, although progress has been made in access to basic education, electricity, piped water, and social protection. Integration of the private and public sectors and of services for HIV, tuberculosis, and non-communicable diseases needs to improve, as do surveillance and information systems. Additionally, successful interventions need to be delivered widely. Transformation of the health system into a national institution that is based on equity and merit and is built on an effective human-resources system could still place South Africa on track to achieve Millennium Development Goals 4, 5, and 6 and would enhance the lives of its citizens.

\section{Introduction}

The 2009 Lancet Health in South Africa Series ${ }^{1}$ coincided with a crucial moment in the life of the nation. A new administration with a committed health minister had just been elected, and the democratic government that had been established 15 years previously was expected to finally jettison the unscientific health policies and disastrous mistakes of the Thabo Mbeki era (1999-2008) made in response to the HIV epidemic, ${ }^{2-4}$ and to overcome shortcomings in the delivery of health and social services. The Series clearly depicted the residual imprint of the colonial and apartheid eras, and the weight of a quadruple disease burden falling on an inequitable and inefficient health system (panel 1)..$^{5-9}$ In the final paper of the Series, ${ }^{10}$ a call for action was made to the South African Government, educational and research institutions, and civil society about measures that were necessary to strengthen the health system.

Here, we focus on themes from the 2009 Series and this report is therefore not necessarily comprehensive. Additionally, we do not mean to imply that a causal relation exists between events that have happened in the past 3 years and the 2009 Series. Nonetheless, it is evident that the Series has been highly influential. The Minster of Health Aaron Motsoaledi opened the launch of the Series in Johannesburg, South Africa, on Aug 24, 2009, ${ }^{11}$ and at subsequent public meetings, he repeatedly referred to its importance in defining of key health challenges that the country faced and the task ahead for his ministry. ${ }^{12}$ The Series is widely quoted and referenced by academics, researchers, policy commentators, and senior staff in the provincial and national Health Ministries. The language of the so-called four colliding epidemics, the substance of the analyses of health problems, and subsequent recommendations have entered the lexicon of health and social literature, complementing other important reports. ${ }^{13}$

Our goal is to assess what progress has been made since 2009, particularly in terms of the specific calls for action to achieve the Millennium Development Goals (MDGs) by 2015. In our view, four important changes have occurred and yet we recognise that four major challenges remain.

\section{Change 1: Leadership as a key driver}

The rapid transition from the failed stewardship of ex-President Thabo Mbeki and the disastrous policies of his health minister Mantombazana Tshabalala-Msimang to the leadership shown by the present health minister Aaron Motsoaledi and his team could not have been more striking. Barbara Hogan took the first steps, initiating several projects to deal with the disarray in the Department of Health in her short term as Minister of Health. These changes were followed by decisive actions, indicating that the government was leading future plans
Published Online November 30, 2012 http://dx.doi.org/10.1016/ S0140-6736(12)61814-5 See Online/Comment http://dx.doi.org/10.1016/ S0140-6736(12)61968-0 and

http://dx.doi.org/10.1016/ S0140-6736(12)61997-7

Department of Medicine, Groote Schuur Hospital and University of Cape Town, Cape Town, South Africa (Prof B M Mayosi DPhil); Saving Newborn Lives, Save the Children, Cape Town, South Africa (J E Lawn MRCP Paeds); Safety and Peace Promotion Research Unit (A van Niekerk PhD) and Burden of Disease Research Unit (D Bradshaw DPhil), Medical Research Council, Cape Town, South Africa; Institute for Social and Health Sciences, University of South Africa, Pretoria, South Africa (A van Niekerk); Centre for the AIDS Programme of Research in South Africa

(Prof S S Abdool Karim PhD) and Department of Paediatrics and Child Health, Nelson R Mandela School of Medicine (Prof H M Coovadia MD), University of KwaZulu-Natal, Durban, South Africa; Department of Epidemiology, Columbia University, New York, NY, USA (Prof S S Abdool Karim); and Maternal Adolescent and Child Health, University of the Witwatersrand, Johannesburg, South Africa

(Prof H M Coovadia)

Correspondence to: Prof Hoosen M Coovadia, Maternal Adolescent and Child Health, 155 Juniper Road, Overport, Durban 4091, South Africa

hcoovadia@match.org.za 
Panel 1: Key messages from 2009 Lancet Health in South Africa Series ${ }^{5-10}$

- 15 years after its first democratic election and liberation from apartheid, South Africa faced four colliding epidemics: HIV and tuberculosis; a high burden of chronic illness and mental health disorders; deaths related to injury and violence; and a silent epidemic of maternal, neonatal, and child mortality. South Africa's per head health burden was the highest of any middle-income country in the world, with the brunt still carried by the poorest families.

- Supportive policies meant moderate spending on health, but health outcomes were worsening. The extra health burden meant that investment in health systems, at least in the medium term, and the effectiveness of implementation and management needed to increase at all levels.

- The health system was under pressure to cope with the heavy burden of disease, especially at district level. Additionally, the public and private sectors were not connected. Three priorities were emphasised:

1 Prevention of infections (notably HIV and tuberculosis); non-communicable diseases; injury; and maternal, neonatal, and child health (especially prevention of mother-to-child HIV transmission and improved neonatal health).

2 Integrated, effective primary health care, with strong management and capable use of data.

3 Widespread scale-up of successful innovations and relevant and rigorous clinical research.

- South Africa was not on track for the Millennium Development Goals, but had potential to be. Other epidemics could have been reduced with strategic investment, implementation, leadership, and accountability for public and private sectors. Civil society had been key in promotion of action for HIV/AIDS and could play a powerful part in the wider health agenda.

and programmes; spending on antiretroviral drugs was accelerated and a new national strategic plan was introduced for HIV, sexually transmitted infections, and tuberculosis for 2012-16. ${ }^{14}$

Leadership, however, extends beyond its most prominent individuals and includes managers and others in positions of responsibility to effect change through their own initiatives. Although at the highest levels, the Minister of Health and his senior staff have made radical policy changes and have had proactive involvement with society, the stasis of more than 10 years in the health management bureaucracy has been slow to change. Managers are particularly important for transformation and service delivery. ${ }^{15}$ They should go beyond routine implementation of rules and instructions from their superiors, and instead use local information to guide and lead change in their areas of responsibility. Gilson and Daire ${ }^{15}$ emphasised that recommendations made in 1998 about delegation of responsibility to facility level and development of managerial training and support ${ }^{16}$ had still not been implemented in 2011, except for the strengthening of management by assessment of performance with a common competency framework. ${ }^{16}$ The development of managerial capacities should be located in a framework that explicitly understands and enables institutional change and addresses the needs of managers. ${ }^{17}$ Development and leadership training should be matched with a systemic plan to transform the dysfunctional civil service into a responsive, caring, and enabling service, which would necessitate restructuring and reorienting of the organisation, rules, and protocols of the present health system.

A central element of leadership is the strength of engagement between the state and its agencies and the population of South Africa. The bond between the key political parties and the people they serve has frayed after many service delivery protests and huge disappointments with overall government performance. A robust longterm strategy of programmes to renew trust through community involvement and effective governance could reduce alienation of the people.

\section{Change 2: Colliding epidemics and health-system responses Overview}

South Africa has experienced a complex health transition in the past two decades. ${ }^{18}$ Mortality worsened between 1990 and 2005, in virtually all age groups largely because of HIV and AIDS. ${ }^{19}$ The morbidity profile is made up of coexisting infectious diseases (including new infections such as HIV and AIDS), non-communicable diseases (NCDs), persisting child diarrhoea and malnutrition, and interpersonal violence and accidents. In the past 3 years, important changes have been made mainly by the government to tackle these formidable health challenges at policy and health-system levels. Although progress in MDG indicators is generally insufficient, several could be at a crucial tipping point, notably mortality of mothers and children younger than 5 years (MDGs 4 and 5; figure 1). Therefore, the timing of this assessment is crucial to inform accelerated action towards 2015.

\section{HIV and tuberculosis}

The government response to the interlinked HIV and tuberculosis epidemics has changed greatly since 2009. Government funding increased from R4 5 billion spent in 2009-10 to R8 . 4 billion budgeted in 2010-11 for expansion of antiretroviral therapy (ART), scaling up of prevention of mother-to-child transmission (pMTCT) programmes, promotion of HIV and tuberculosis treatment integration, and increased investments in HIV prevention..$^{20}$

One of the biggest obstacles to HIV prevention and treatment is poor knowledge or denial about HIV status and the associated risk. Discrimination and social marginalisation continue to be experienced daily by people who are the most affected by HIV. ${ }^{21}$ These social exclusions further contribute to their reluctance to test for HIV. To address this issue, an aggressive national campaign was launched in South Africa in April, 2010, to encourage 15 million sexually active individuals to be tested for HIV..$^{22}$ At the end of the campaign in June, 2011, 14.8 million counselling sessions and 13 million tests for HIV, and 8 million tests for tuberculosis had been completed, although how many patients who tested positive were referred is unknown. ${ }^{23}$ 


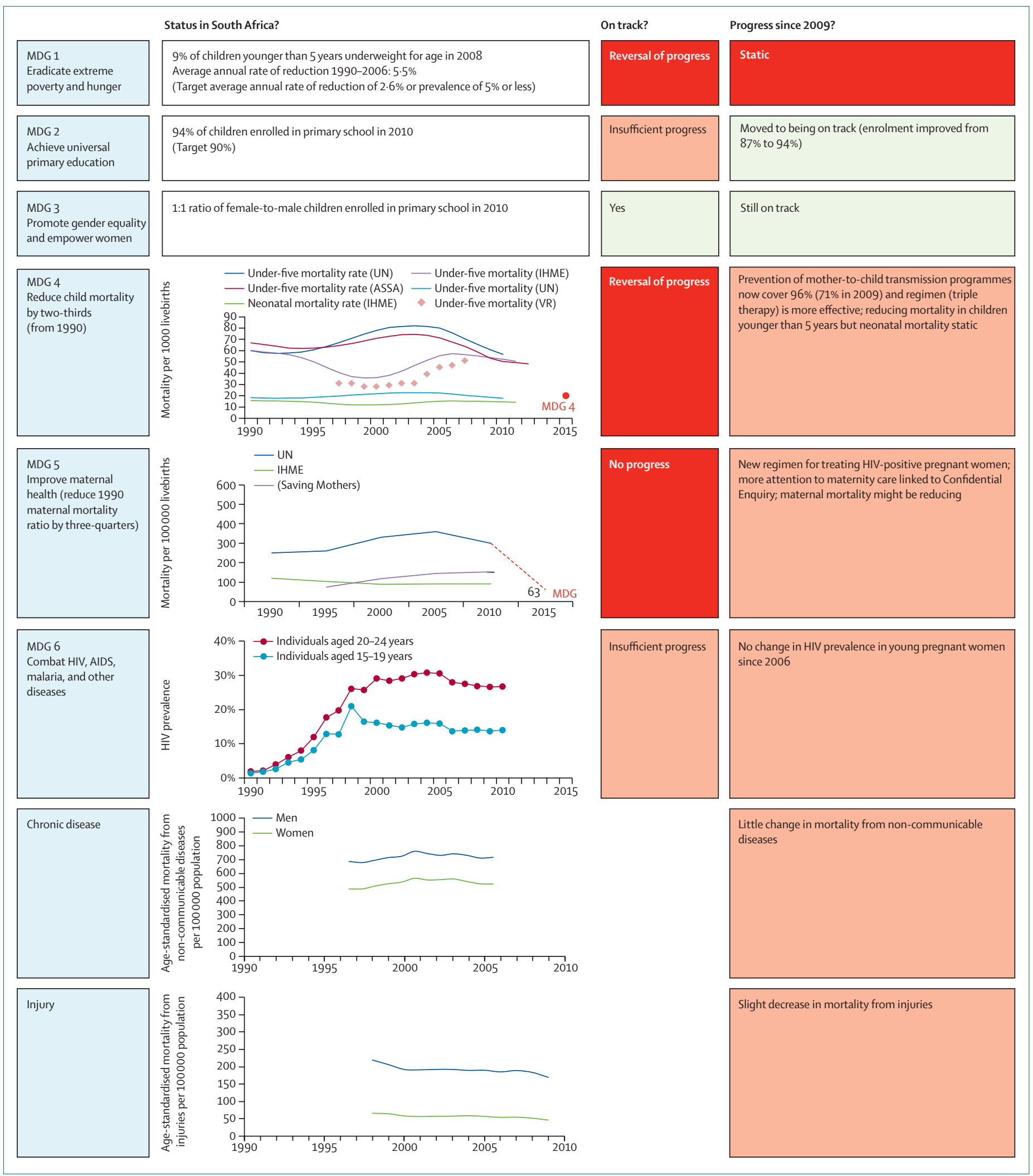

Figure 1: Progress towards MDGs 1-6 and for non-communicable diseases and injury

MDG=Millennium Development Goal. ASSA=Academy of Science of South Africa. IHME=Institute for Health Metrics and Evaluation. VR=vital registration. 
Important gains have been achieved in the scale-up of prevention methods such as condoms, circumcision, and pMTCT. Male condom distribution increased greatly from 2006 to 2010 (table 1). ${ }^{20}$ Although not on the same scale, distribution of female condoms also increased in the same period (table 1). ${ }^{20}$ Medical male circumcision has become a priority component of HIV prevention in South Africa. Introduced in 2007, the number of medical male circumcisions rose substantially between 2008 and 2011 (table 1), because of local evidence of effect. ${ }^{32}$

South Africa continues to have the largest ART programme in the world, with about 1.8 million people estimated to be taking antiretrovirals by April, 2011 (table 1). ART services are now available in more than 2552 approved facilities countrywide. ${ }^{23}$ Roughly half of individuals in need of ART were receiving treatment in South Africa in 2011 (table 1), which is an increase attributed to the new guidelines for treatment initiation when CD4 count is less than 350 cells per $\mu \mathrm{L}^{27,28}$ The government is simultaneously transitioning thousands of patients from treatment programmes funded by the US President's Emergency Plan for AIDS Relief to government services. Expansion of access to treatment has started to affect AIDS mortality, with the proportion of overall deaths that are related to AIDS decreasing between 2006 and 2011 (table 1). Estimates of life expectancy indicate an increase from a low of 54 years in 2005, to 60 years in 2011. ${ }^{33}$ Expansion of treatment to the individuals who need ART but are not receiving it is a challenge to the capacity of the health service.

Malaria-a major cause of morbidity and mortality in southern Africa-has largely been contained and restricted in South Africa to the areas bordering Mozambique. In 2010, fewer than 8000 cases and 81 deaths were recorded. ${ }^{34}$ About $55 \%$ of malaria cases are estimated to be imported and not due to local transmission. ${ }^{34}$ South Africa has adopted a strategy which aims to eliminate malaria in the country by $2018 .{ }^{34}$

However, the tuberculosis epidemic continues unabated. In 2010, 401048 tuberculosis cases were reported in South Africa. ${ }^{35}$ Although some improvement has been made in detection of tuberculosis-increasing between 2006 and 2010 (table 1$)^{30}$-the treatment success frequency is still far below the target of $85 \%$ (table 1). In 2010, 5402 patients with multidrug-resistant tuberculosis were registered in South Africa, which was the third highest number in the world..$^{30}$ The National Tuberculosis Control Programme is implementing the Xpert MTB/RIF diagnostic system as a replacement for sputum smear microscopy in all laboratories in South Africa to improve case detection and identify rifampicin-resistant cases early so that appropriate treatment can be initiated. ${ }^{36}$ South Africa now has the largest Xpert MTB/RIF implementation programme in the world; the country's National Health Laboratory Service did 472734 tests between March, 2011, and July, 2012. ${ }^{36}$ The effect of Xpert MTB/RIF on patient, programme, and population-level outcomes is being formally assessed in a large cluster-randomised trial nested in the national roll-out. ${ }^{36}$

Unfortunately, South Africa did not meet the ambitious targets of $50 \%$ reduction in HIV incidence and $80 \%$ ART coverage of the National HIV/AIDS and STI Strategic Plan for 2007-11. ${ }^{37}$ Under the previous plan, HIV frequency in pregnant women rose slightly from $29 \cdot 1 \%$

\begin{tabular}{|c|c|c|c|c|c|c|}
\hline & 2006 & 2007 & 2008 & 2009 & 2010 & 2011 \\
\hline \multicolumn{7}{|l|}{ HIV/AIDS indicators } \\
\hline People living with HIV (million) & 4.99 & $5 \cdot 27$ & $5 \cdot 13$ & $5 \cdot 35$ & $5 \cdot 47$ & $5 \cdot 58$ \\
\hline Antenatal HIV frequency (\%) & $29 \cdot 1 \%$ & $29 \cdot 4 \%$ & $29 \cdot 3 \%$ & $29 \cdot 4 \%$ & $30 \cdot 2 \%$ & NA \\
\hline HIV frequency in the total population (\%) ${ }^{24}$ & $10 \cdot 2 \%$ & $10 \cdot 2 \%$ & $10 \cdot 6 \%{ }^{25}$ & $10 \cdot 4 \%$ & $10 \cdot 5 \%$ & $10 \cdot 6 \%$ \\
\hline Male condoms distributed (million) & 376 & $453^{26}$ & $284^{20}$ & $445^{20}$ & $492^{20}$ & 347 \\
\hline Female condoms distributed (million) & 3.6 & $3 \cdot 3^{26}$ & $4 \cdot 3^{20}$ & $3 \cdot 6^{20}$ & $5 \cdot 0^{20}$ & $6 \cdot 4$ \\
\hline Adult medical male circumcisions ${ }^{23,27}$ & NA & NA & 5190 & 9168 & 121117 & 347973 \\
\hline Adults and children receiving antiretroviral therapy ${ }^{28}$ & 235000 & 382000 & 588000 & 912000 & 1287000 & 1793000 \\
\hline Antiretroviral coverage $(\%)^{27-29}$ & $19 \%$ & $28 \%$ & $35 \%$ & $51 \%{ }^{*} / 29 \% \dagger$ & $64 \%{ }^{*} / 39 \% \dagger$ & $79 \% * / 52 \% \dagger$ \\
\hline Deaths due to HIV/AIDS (\%) & $52 \cdot 3 \%$ & $51 \cdot 2 \%$ & $49 \cdot 2 \%$ & $46 \cdot 4 \%$ & $44 \cdot 3 \%$ & $43 \cdot 6 \%$ \\
\hline \multicolumn{7}{|l|}{ Tuberculosis indicators } \\
\hline Prevalence (all forms; per 100000 people) ${ }^{30}$ & 797 & 789 & 792 & 809 & 795 & NA \\
\hline $\begin{array}{l}\text { Estimated incidence (all forms; per } \\
100000 \text { population) }\end{array}$ & 940 & 948 & 960 & 971 & 981 & NA \\
\hline Estimated number of incident cases (all forms) & 450000 & 460000 & 470000 & 480000 & 490000 & NA \\
\hline Case detection $(\%)^{30}$ & $67 \%$ & $68 \%$ & $73 \%$ & $75 \%$ & $72 \%$ & NA \\
\hline Treatment success of new smear positive cases $(\%)^{30,31}$ & $74 \%$ & $74 \%$ & $76 \%$ & $73 \%$ & $73 \%$ & $80 \%$ \\
\hline Death rate (per 100000 population) $)^{30}$ & 57 & 53 & 51 & 52 & 50 & NA \\
\hline Patients with HIV co-infection ${ }^{30}(\%)$ & $59 \%$ & $59 \%$ & $59 \%$ & $58 \%$ & $60 \%$ & $65 \%$ \\
\hline
\end{tabular}


in 2006 , to $30 \cdot 2 \% 2010$, and it increased in the general population from $10 \cdot 2 \%$ in 2006 , to $10 \cdot 6 \%$ in $2011 .{ }^{24}$ These increases probably represent a success of the treatment programme, with increased numbers of people with HIV staying alive and raising the prevalence. ${ }^{24}$ Through a detailed consultative and inclusive process, a new plan has been developed for 2012-16. ${ }^{23}$ The new plan sets the same ambitious HIV incidence and treatment targets as the previous plan and establishes several other targets, such as a $50 \%$ reduction in new tuberculosis cases and deaths, 30 million people tested for HIV by 2016, and a further reduction in mother-to-child transmission to less than $2 \%$ at 6 weeks after birth..$^{23}$ Transformation of political commitment into well planned and effectively implemented evidence-based programmes and services will be essential to achieve the lofty goals of the new plan.

\section{Maternal, neonatal, and child health}

Because of the HIV epidemic and underperformance of the health system, South Africa was one of only a dozen countries worldwide with increased mortality since 1990 for MDGs 4 (child survival) and 5 (maternal health) in 2009. ${ }^{10}$ In terms of maternal, neonatal, and child health, the Series called for a focus on reaching all families with effective maternal and neonatal care through strengthening of primary-care services, notably in district hospitals where $25-50 \%$ of deaths had been affected by an avoidable health-system factor. Additionally, prioritisation of the scale-up of pMTCT, care of women with HIV, and maternal and neonatal care was emphasised in the Series, which illustrated that rapid action could still put South Africa on track for MDG 4 and possibly MDG 5.

Since 2009, HIV treatment for pregnant women has received increased policy focus with changes in treatment threshold and investment for scale-up. ${ }^{38}$ However, this effort is threatened by stock depletion because of rapid increases in the number of people taking ART and the effect on maternal mortality is less clear. ${ }^{33,39}$ Community effects of pMTCT programmes are also now evident. Within 10 years of the initiation of the country's pMTCT programme, $95 \%$ of all health facilities were providing this service in 2010. South Africa is also one of four countries that has achieved more than $80 \%$ coverage of antiretroviral prophylaxis for pMTCT. ${ }^{40}$ More than $98 \%$ of women receive an HIV test during pregnancy and $91.7 \%$ of HIV-positive mothers are receiving ART or prophylaxis. ${ }^{41}$ A national assessment of 10178 infants in 572 health facilities showed that the 6-week vertical transmission rate was $2.7 \%$ in 2011 compared with $20-30 \%$ in the preceding decade. ${ }^{42}$ Aggressive regimens and almost full coverage have also contributed to the progress in pMTCT.

The key challenge for pMTCT is no longer drug treatment at the time of birth, but feeding support in the postnatal period. Changes since 2010 in policies about infant feeding shift the emphasis to exclusive breastfeeding, which is welcome not only for HIV-affected families, but also for all families because suboptimum infant feeding has a large effect on postnatal transmission of HIV. ${ }^{43}$ The frequency of exclusive breastfeeding to 6 months in South Africa remains one of the lowest in the world at $8 \%,{ }^{41}$ although surveys report some improvements since the introduction of new policies about infant feeding. ${ }^{42}$

Re-engineering of primary health care and plans for national health insurance have been important national themes. Innovations for maternal, neonatal, and child health emphasised in the Series have received specific attention; for example, community health workers visit pregnant women and new mothers in their homes. ${ }^{6}$ Additionally, mentor teams for maternal, neonatal, and child health-introduced in the Series-are now being introduced nationally. ${ }^{6}$ The teams consist of an obstetrician, midwife, paediatrician, paediatric nurse, an anaesthetist, a family medicine specialist, and a primary health-care nurse. Their main role is clinical governance and training to address quality of care for mothers, newborn babies, and children.

Re-engineering of primary health care has underlined the need to strengthen facilities, because a functional community and primary health-care system increases use of high-level hospital services. A nationally agreed programme to improve quality of emergency obstetric and neonatal care is being implemented in 25 health districts and assessed through a stepped wedge trial funded by the UK Department for International Development (Pattinson R, University of Pretoria, personal communication). The Campaign to Accelerate the Reduction in Maternal Mortality in Africa has also been launched, which integrates antenatal, family planning, child health, and school health services with HIV risk reduction and ART strategies. ${ }^{44}$ It goes beyond pMTCT because, in addition to ART initiation irrespective of CD4 count, it also invests in prevention of unwanted pregnancies in adolescence-a key contributor to maternal and neonatal deaths. Additionally, the campaign introduces an approach to prioritise so-called hotspots with high disease burden as priority points for service delivery.

Increased accountability for results, especially health outcomes, is crucial. The establishment of three national committees (maternal, perinatal, and child mortality) ${ }^{45-47}$ reporting directly to the Minister of Health has been a step forward in increasing the profile and coordinated action for maternal, neonatal, and child health, linking national mortality audit data to action and transferring lessons learned in one province to others. Yet reliable national mortality data for women and children are scarce and other key gaps remain for decision making. ${ }^{48}$ These data gaps and lags impede progress at a time when course correction could conceivably still place South Africa on track for MDGs 4 and possibly 5 (figure 1; appendix).

\section{Non-communicable diseases and mental health}

In 2009, we reported the emergence of NCDs and mental illness in rural communities, the heavy disease burden on poor urban communities, and the interaction 
between infectious diseases (eg, tuberculosis) with chronic diseases (eg, chronic lung disease). ${ }^{8}$ The link between infectious diseases and NCDs is increasingly being recognised by WHO and others, and provides a basis for a coordinated and integrated health-service response to care. ${ }^{49,50}$ With the exception of tobacco use, ${ }^{51}$ South African data show that the pattern of risk factors for NCDs has deteriorated substantially in the past two decades and that detection, management, and outcomes of care for individuals with NCDs are suboptimum..$^{52}$

Global attention on $\mathrm{NCDs}^{53}$ provided impetus for a national summit on NCDs convened by the South African Ministry of Health in September, 2011. The major advance that arose from the summit is that South Africa has set targets to radically reduce NCDs through a set of commitments with time limits contained in the South African Declaration on the Prevention and Control of Non-Communicable Diseases, which was issued ahead of the UN Summit on Non-Communicable Diseases (panel 2). ${ }^{54}$ The Ministry of Health has already taken action to formulate legislation to reduce the mean population intake of salt from the present level of 8-10 g/day to less than $5 \mathrm{~g} /$ day by 2020. The proposed reductions should result in 7400 fewer cardiovascular deaths and 4300 fewer non-fatal strokes per year in 2011 than in 2008, and cost savings of up to R300 million per year. ${ }^{55}$

A national NCD plan is being developed by the government, and a project has been set up to pilot integrated care in the facilities of three districts. The Ministry of Health has signalled its intention to curb alcohol advertising in the country, ${ }^{56}$ and is supported by the Colleges of Medicine of South Africa and other academic leaders worldwide. ${ }^{57}$ The causal links between alcohol and unsafe sex, HIV infection, tuberculosis, liver disease, mental illness, and injury have underlined the urgency for the implementation of the WHO's global strategy to

Panel 2: Targets for reducing non-communicable diseases in South Africa by the year 2020

1 Reduce premature deaths (ie, $<60$ years) from non-communicable disease by $25 \%$

2 Reduce tobacco use by $20 \%$

3 Reduce per head consumption of alcohol by $20 \%$

4 Reduce mean salt intake to less than $5 \mathrm{~g} /$ day

5 Reduce prevalence of obesity and overweight by $10 \%$

6 Increase prevalence of physical activity (defined as 150 min of moderate-intensity physical activity per week) by $10 \%$

7 Reduce prevalence of hypertension by $20 \%$ through lifestyle modification and medication

8 Increase proportion of people receiving treatment for control of hypertension, diabetes, and asthma by $30 \%$

9 Offer screening to women with sexually transmitted diseases for cervical cancer at least once every 5 years, or to every woman at least three times in a lifetime

10 Increase number of people screened and treated for mental illness by $30 \%$ (by 2030)

Reproduced from the South African Declaration on the Prevention and Control of Non-Communicable Diseases, ${ }^{54}$ by permission of the Department of Health. reduce harmful use of alcohol..$^{58-60}$ Furthermore, a review of mental health services ${ }^{61}$ showed that progress has been made in the decentralisation of care from tertiary hospitals to districts and communities. However, the challenge remains to scale up appropriate mental health services for the benefit of the whole population. ${ }^{62}$

Cause-of-death statistics indicate that overall mortality from NCDs has hardly changed in the past 10 years, although changes have been reported for specific causes (figures 1, 2). The number of deaths attributed to some disorders-eg, asthma-has increased in younger age groups, potentially reflecting rises in the number of deaths due to HIV infection; deaths from HIV are frequently attributed to other diseases that coexist with the infection. Hypertensive heart disease, diabetes mellitus, and renal disease increased in all individuals, but stroke did not rise after a peak in 2003 in individuals aged 65 years or older and decreased in the younger group (figure 2). Ischaemic heart disease seems to have fallen slightly, as have chronic obstructive pulmonary disease, lung cancer, and oesophageal cancer (figure 2). Breast and cervical cancers in women and prostate cancer in men increased (figure 2).

The prospects of an effective national NCD surveillance system-essential to inform strategic planning and policy-have been boosted by the launch of the South African National Health and Nutrition Examination Survey by the Human Sciences Research Council. ${ }^{64}$ The survey is a prospective cohort study that aims to establish the health and nutritional status of South Africans of all ages to support the priority health indicators of the Ministry of Health. This comprehensive surveillance project will assess the prevalence of NCDs and their risk factors, the health status of children, and the behavioural and social determinants of health. Measurement of mortality and morbidity is an essential step in tracking of targets for combating NCDs and mental illness in South Africa. ${ }^{8}$

\section{Violence and injury}

The 2009 Series called for an integrated national response to South Africa's heavy burden of disease from injury and violence, ${ }^{9}$ emphasising the need to combat societal determinants. Indications suggest that injury mortality has decreased in the past decade (figure 1). ${ }^{65}$ This overall fall is also reflected in the indicators of homicide and traffic mortality, with possible substantial declines reported in recent years (panel 3). However, reviews of evidence for gender-based violence suggest that no reduction has occurred in the past decade (Jewkes R, South African Medical Research Council, personal communication).

The national response in the past 3 years continued to emphasise criminal-justice enforcement with few infrastructural responses to prioritise injury prevention issues $^{70}$ such as interpersonal violence, ${ }^{72}$ violence against women and girls, ${ }^{73}$ male youth violence, ${ }^{747}$ child and youth safety, ${ }^{7}$ and traffic safety. ${ }^{78,79}$ However, the importance of 

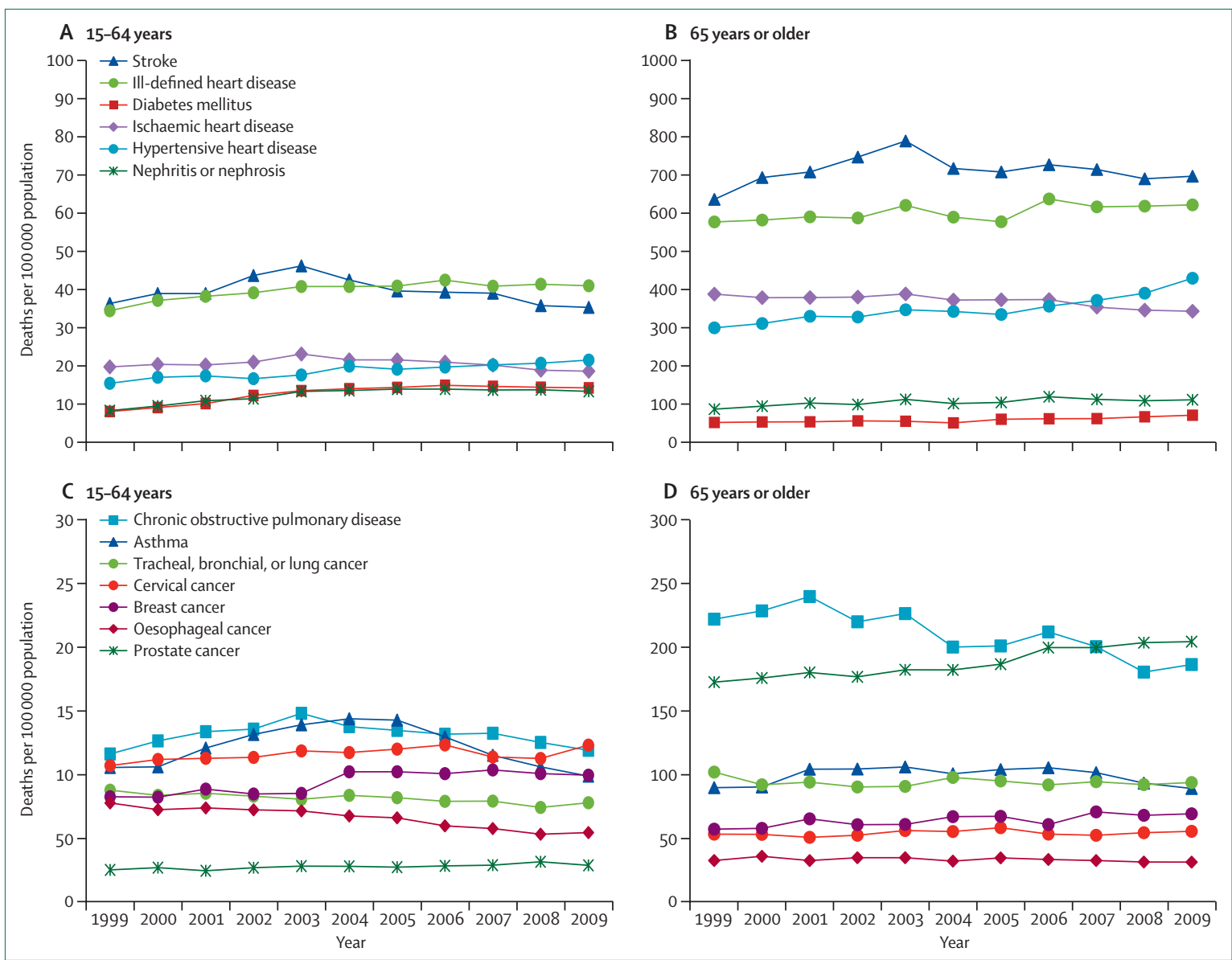

Figure 2: Mortality per 100000 people from cardiovascular and related diseases (A, B) and some respiratory diseases and common cancers (C, D) Calculations based on data from Statistics South Africa. ${ }^{63}$

tackling some of the priority cross-cutting determinants mentioned in the Series ${ }^{9}$ is increasingly recognised (appendix), particularly widespread access to firearms and alcohol and drug misuse. ${ }^{9,13}$ For example, policy efforts were strengthened at the Second Biennial Substance Abuse Summit hosted by the Department of Social Development; ${ }^{80}$ strategies to enhance implementation of existing legislation were emphasised, such as provincial policy alignment, increased enforcement on sales restrictions, and a reduced legal alcohol limit for vehicle drivers. Implementation is variable; for example, the legal alcohol limit has not been decreased as yet. However, arrests for driving under the influence of alcohol or drugs increased significantly from 56165 in 2009-10, to 66697 in 2010-11, ${ }^{66}$ suggesting intense enforcement efforts.

Evidence is available for a positive effect of the legislation on female gun-related homicide, with 1147 such cases in 1999, compared with 461 in $2009 .{ }^{81}$ Firearm control measures have also been further consolidated. Section 136(1) of the Firearms Control Act legislates for the destruction of firearms surrendered or forfeited to the state and consolidates the national campaign to reduce the country's high number of firearms ( 3 million firearm owners are registered) ${ }^{66}$ The number of illegal firearms has been reduced by at least $24 \%$ since the Firearms Control Act was implemented in 2004. ${ }^{82}$ Between January and June, 2012, a further 2632 firearms have been destroyed. Additionally, the Commission of Enquiry into the operations of firearm dealerships seeks to enforce restrictions to firearms purchase. However, with 5362 South African Police Service firearms lost or stolen between 2008 and 2010, there are concerns about the police's own firearm security measures as well as the control of the pool of illegal firearms. ${ }^{83}$ Furthermore, concerns about the police's approach to enforcement have manifested, particularly in response to community protests and, in 2012, to industrial protests. Reports have suggested that many people have been shot dead or assaulted by the police, ${ }^{84}$ although official complaints about deaths caused by the police have been steadily decreasing, from 912 in 2008-09, to 797 in 2010-11. . $^{85}$

In 2009, the Department of Women, Children and Persons with Disability was formed and in 2012, it established a National Council Against Gender-Based Violence. This group is chaired by the Deputy President of South Africa, includes representatives from civil 
Panel 3: Falling homicide and traffic-injury mortality

The South African Police Service has reported a steady reduction in homicide nationally, from 40.5 per 100000 people in 2006, to 31 per 100000 in $2010 .{ }^{66} \mathrm{~A}$ marginal decrease in traffic mortality has been reported by the Department of Transport, from 28.1 per 100000 in 2009, to 27.5 per 100000 in 2010. ${ }^{67}$ These national rates are corroborated by the falls reported by the mandatory, mortuary-based National Injury Mortality Surveillance System for the urban Gauteng province, with homicide reducing from 51.7 per 100000 in 2008, to 42.7 per 100000 in 2010, and traffic mortality reducing from 46.3 per 100000 in 2008, to 39.7 per 100000 in $2010 .{ }^{68}$ Similar trends have been reported in the predominantly rural Mpumalanga province, with homicide falling from 33.2 per 100000 in 2009, to 25.9 per 100000 in 2010, and traffic mortality reducing from 68.4 per 100000 to 57.2 per 100000 (a greater rate of decrease than nationally). ${ }^{69}$

Serious inconsistencies exist between the available national information sources (ie, from National Injury Mortality Surveillance System, the South African Police Service, and the Department of Transport) and challenges related to the under-reporting by the agencies continue. ${ }^{70,71} \mathrm{~A}$ national integrated injury information system building on the pre-existing systems that has been extended to incorporate the automation of specific data collection and analytic and dissemination components has been recommended (unpublished).

society, will advise the government, and will monitor and review implementation of prevention policy and programming. Furthermore, the Directors-General of the Human Development Cluster have mandated that the Department of Health should develop an integrated strategic framework for the prevention of injury and violence involving ten government departments. This framework will be aligned to the World Report on Violence and Health in its prioritisation of a national plan that incorporates existing violence-prevention legislation and policy, building of data collection and research capacity, development of prevention responses, and strengthening of services for victims. ${ }^{86,87}$ It targets the risk factors specific to priority injuries, particularly those due to violence and traffic crashes, and emphasises common determinants and promotion of supportive institutional factors. These initiatives are to be welcomed. Successful implementation necessitates prioritisation of evidencebased intervention, investment in surveillance systems, and improved human resources and management capacity. State-sponsored violence-such as that exhibited by the South African police response to aggressive striking miners at Marikana in 2012-is still a real and continuing limitation to controlling violence of all forms.

\section{Change 3: Towards universal coverage with national health insurance}

About seven previous attempts to introduce a health scheme with progressive features began with the Commission on Old Age Pension and National Insurance in 1928, which was followed by different committees and commissions and the present Ministerial Advisory Committee on national health insurance, which was introduced in 2009. The best known iteration was the National Health Service (or Gluckman Commission; 1942-44), which recommended a tax for funding of health services. ${ }^{88}$ The call for action from the 2009 Series ${ }^{10}$ urged the South African Government to discuss a system of national health insurance to guarantee universal health coverage. ${ }^{89}$ National health insurance, which will be phased in for 14 years, is envisaged to gradually transform the existing unequal and racially skewed health system into a national institution based on equity, social solidarity, fairness, affordability, appropriateness, and effectiveness. ${ }^{90}$

The new framework aims particularly to overcome the inequities and inefficiencies of the present two-tier system of a well resourced private sector and a poorly resourced public sector (figure 3). 1,3,90,91 The inequities in access to health care are worsening; ${ }^{92}$ in the past decade, private hospital and specialist costs have increased to more than the consumer price index, ${ }^{93}$ and distribution of specific skilled human resources is skewed to the advantage of the private sector. The arguments in favour of national health insurance and comparisons with other countries have been provided in a policy paper ${ }^{90}$ and reported in studies. ${ }^{91,94}$ Strengthening of the public health service is a fundamental first step towards achievement of an effective system of national health insurance. A reengineered system of primary health care will improve the balance between community-based promotive and preventive services and hospital-centred curative care (figure 4). Quality control and regulation will be implemented through the Office of Health Standards Compliance. National health insurance will be funded from a number of sources including a mandatory tax, the public treasury, and from a payroll tax (panel 4). ${ }^{90}$

Costing of national health insurance has been supported $^{95}$ and criticised by local economists. ${ }^{96}$ Critics suggest that administration costs are underestimated and the predicted growth in the country's economy is too optimistic; other criticisms are based on inappropriate market-related solutions. The 2012 budget $^{97}$ anticipates that the real growth of the gross domestic product will stabilise to $4 \cdot 2 \%$ per annum by 2014 . A KPMG report ${ }^{94}$ is much more optimistic and draws attention to the benefits of externalities: health care has a $5 \%$ multiplier effect through increased life expectancy and labour productivity. ${ }^{97}$ Much more operational and implementation research will be needed in view of the complexity and scale of the transformation necessary to establish national health insurance in South Africa.

Progress with national health insurance since the release of the policy paper has been regularly reported in the media. ${ }^{98}$ National health insurance has been piloted in ten selected health districts throughout the country. Other activities include the development of health service quality norms and standards through an Office of Health Standards Compliance to improve the quality of care in public health care. More than $75 \%$ of all public health facilities have already been audited: few facilities comply with existing standards and norms. Long waiting times and interruption of treatment due to non-availability of medicines are common. ${ }^{92}$ 


\section{Change 4: Consensus about health research}

Wieland Gevers drew attention to the parlous state of clinical research in South Africa in 2009. ${ }^{99}$ The serious decline in clinical research activity and capacity prompted the Academy of Science of South Africa to produce recommendations for revitalisation of clinical research, such as increased funding, training of a new generation of health researchers, establishment of clinical research centres, and improved regulation and planning of the health research enterprise. ${ }^{100}$ The Department of Health also recognised the essential role of health research in achievement of a long and healthy life for all South Africans through its ten-point plan for 2009-14, ${ }^{101}$ which includes "strengthening of research and development" as its tenth priority.

The National Health Research Committee acted on this commitment by convening a national health research summit in July, 2011, which set seven priorities for health research in South Africa. ${ }^{102}$ These priorities, which have been accepted by the Ministry of Health, promise to improve the quality of research in South Africa and call for several actions. First, funding for health research by the Department of Health as a signatory of the Bamako Declaration should increase from $0.37 \%$ to $2.0 \%$ of the national health budget. ${ }^{103}$ Second, a new generation of health researchers should receive training through a national health scholars programme, especially black people and women. Third, health research infrastructure needs to be developed in the Academic Health Complexes to enable research-based re-engineering of primary health care through funding of clinical research centres. ${ }^{104}$ Fourth, priority research projects designed to increase the lifespan of South Africans should be funded through a national priority research projects fund. Fifth, the national regulatory framework for health research should be improved. Sixth, a national mechanism needs to be created for the timely translation of research findings into policy, programmes, and practice. Finally, a national system should be developed for evidence-based planning and monitoring and assessment of the effectiveness and effects of the health research system on the burden of disease in South Africa. A national health scholars programme that aims to give 1000 doctorates in the health sciences in the next 10 years has been launched as a first step to address the seven priorities for the rejuvenation of health research in the country. ${ }^{105}$

The remarkable alignment between the priorities of the new leadership of the Department of Health, the scientific advice of expert committees, and the health research community has resulted in a rapid translation of recommendations to revitalise the health research system in South Africa. ${ }^{106}$ An editorial in the South African Journal of Science ${ }^{106}$ commented that "The present case is an example of how government policymaking can be productively influenced, by an expert committee (in this case the [National Health Research Committee]) acting on recommendations which were made by a panel appointed and

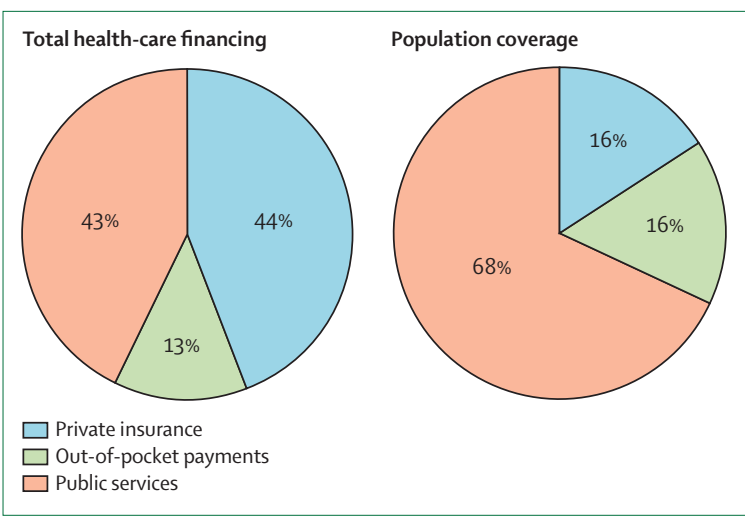

Figure 3: Health financing and population coverage

$16 \%$ of individuals pay to see private doctors and dentists, but use public

hospitals for serious illnesses; they often buy over-the-counter drugs and cannot afford large health-care expenses. Most out-of-pocket expenditure is copayments for private insurance; the private sector maintains that they claim for individuals who make copayments, but this claim is inaccurate. Figure based on data from the Department of Health..$^{90}$

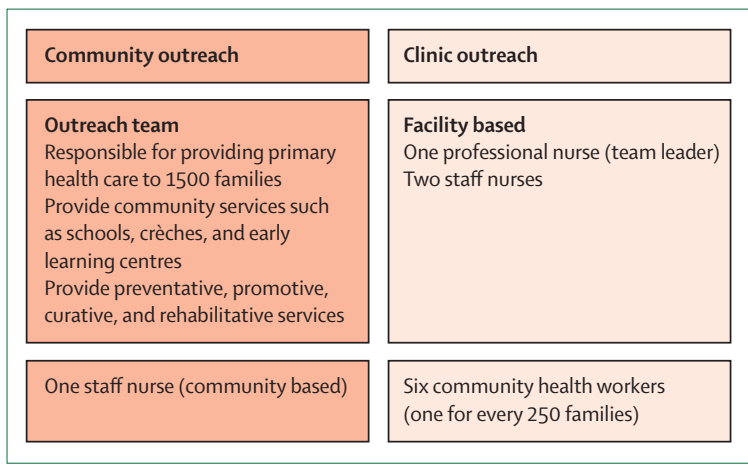

Figure 4: Re-engineered primary health care with national health insurance Three mechanisms are proposed for delivery of defined packages of care: district-based clinical specialist teams; school-based primary health-care services; and municipal primary health-care agents. Payment for primary health care will be through a risk-adjusted capitation system that is linked to performance, registered population size, epidemiological profiles, use, and cost. Hospital benefits will be provided according to the level of care and referral systems. Accredited and contracted hospitals will be reimbursed initially with global budgets and subsequently with diagnosis-related groups. Figure based on information from the Department of Health. ${ }^{90}$

managed by an independent national science academy ([Academy of Science of South Africa]) and debated by a cross section of stakeholders in the community. This process could be widely applied to the benefit of our society."

\section{Challenge 1: Social determinants and racial disparities}

Many data show that health and wealth are mutually reinforcing and that national pro-poor policies for economic growth also contribute to health and improved health outcomes contribute to economic development. ${ }^{107}$ Countries such as Brazil have shown these changes at scale. ${ }^{108}$ The most important reasons why South Africa has not achieved social and economic development in the past two decades are poverty, unemployment, sexism, and socioeconomic inequity. ${ }^{13}$ These factors are the core 
Panel 4: Estimates of cost and proposed sources of funds for national

health insurance ${ }^{90,91,94}$

Estimates of cost

- Model 1: ZAR125 billion in 2012 (4.2\% of GDP); R255 billion in 2025 ( $6 \cdot 2 \%$ of GDP)

- Model 2: R128 billion in 2012 (4.3\% of GDP); R375.5 billion in 2025 ( $9.1 \%$ of GDP)

- Model 3: R10.4 billion per year

Revenue sources

- Progressive (ie, high-income groups contribute higher proportions of their income than do low-income groups): income taxes (direct), sales taxes, health insurance for formal sector workers (ie, employees who work in government and industry and usually have unionised rights)

- Regressive (ie, low-income groups contribute higher proportions of their income than do high-income groups): health insurance for informal sector workers (ie, who do casual labour and do not generally have unionised rights), out-of-pocket payments, private health insurance, indirect taxes

Additional budget for period of roll-out of model 3

- Income tax at $1.1 \%$

- Value added tax at $0.8 \%$

- $46 \%$ increase in excise duties on alcohol and cigarettes

$\mathrm{GDP}=$ gross domestic product. dependency grants grew by about $6 \%$. However, the wealth inequalities have been growing. ${ }^{112}$

\section{Challenge 2: Integration and coordination}

Integration of aspects of the South African health system-eg, the public and private sectors, vertical programmes, and community outreach-will be challenging. Coordination and partnerships between public and private sectors of health care are possible (as with national health insurance) but will have to be carefully monitored for efficacy; integration seems highly unlikely and is probably undesirable. Integration of tuberculosis and HIV services and of wide service delivery for maternal, neonatal, and child health and NCDs still need to be addressed. WHO estimates that $60 \%$ of patients with tuberculosis in South Africa tested for HIV received positive results in 2010. ${ }^{30}$ Even though compelling evidence exists for the benefit of early ART initiation in patients with both tuberculosis and HIV ${ }^{113}$-particularly those who are severely immunocompromised ${ }^{114,115}$ —only about half of all patients with tuberculosis are aware of their HIV status. ${ }^{30}$ South Africa has the largest programme of isoniazid treatment for tuberculosis prevention in the world: 372994 people started isoniazid preventive treatment in 2011. ${ }^{116}$ Although the progress has been remarkable, more than $80 \%$ of eligible people with HIV have not received this treatment. ${ }^{116}$

An important feature of the HIV testing campaign in $2011^{22}$ was that it was provided as part of a package of health services including interventions for high blood pressure, diabetes, anaemia, sexually transmitted infections, and tuberculosis. Although the achievement of the campaign is laudable, linkage to care was not optimised, with few patients with HIV effectively followed up in continuing prevention and care services. The struggling public healthcare system is a deterrent to many who try to obtain medical help; its improvement is crucial for long-term sustainable provision of ART and management of chronic disorders. Experiences with integrated care need to be shared and quickly adopted. District and provincial management need to find ways in which enhancements can be extended from one facility to another.

Coordination across sectors and engagement with civil society are also important and were emphasised as missed opportunities in $2009 .{ }^{10}$ The African National Congress has attempted to re-engage with communities and social partners; such communication between groups was an abiding feature during the struggle for freedom but had diminished since independence in 1994. Civil organisations-such as the Treatment Action Campaign, People's Health Movement, and Section 27-have been especially active for HIV and are making valuable contributions. South Africa's National AIDS Council was established in 2000, to provide multisectoral leadership, political oversight, and guidance for South Africa's HIV/ AIDS programme. In 2007, it endorsed a National Strategic Plan for HIV and AIDS and STIs to run for 4 years that 
would oversee continual monitoring and assessment of the programme. However, a mid-term review identified serious difficulties: the many poorly defined targets and weak coordination had seriously hampered reporting of national progress..$^{14}$ Nonetheless, outcomes in the health sector have been recorded in a country progress report on AIDS, ${ }^{117}$ which entailed an inclusive process of consultation between government, civil society, the business sector, and development partners, reflecting the continued engagement of different sectors that has been achieved.

The advantages and disadvantages of a structure similar to that of South Africa's National AIDS Council are being considered as national plans are made for both NCDs and injury prevention. However, many feel that existing structures should be used. For example, the cluster structure in government creates platforms for interdepartmental cooperation and the Negotiated Service Delivery Agreement-a charter reflecting the commitment of the South African Government and its partners to achieving 12 key outcomes as indicators - has defined a programme of action for 2010-14. ${ }^{118}$ Although interministerial agreements have been established, the coordination of implementation at many levels remains a challenge.

\section{Challenge 3: Surveillance and information}

In 2011, the National Department of Health established a Health Data Advisory and Co-ordinating Committee which has identified key indicators and data sources to be used to monitor the performance of the health ministry. ${ }^{119}$ Additionally, efforts to strengthen the information systems were supported by policies and an audit of infrastructure and resources. ${ }^{120}$ However, South Africa can be judged to be data rich but information poor, because the data systems might not provide nationally representative, good-quality information in a timely manner in view of the rapid changes in health outcomes that have probably occurred in the past few years.

Several sets of estimates for maternal and child mortality suggest that possibly rapid change has occurred in the past 3 years, yet inconsistent numbers dilute policy and programme response. ${ }^{48}$ Mortality statistics from vital registration have improved and, for the first time, national mortality indicators based on vital registration have been reported, but their use to measure trends-especially those for specific causes of death-remains difficult. ${ }^{33,121-123}$ Efforts have been initiated to improve coding and quality of cause-of-death certification (Tuoane-Nkhasi M, Statistics South Africa, personal communication). A programme to train doctors in the public sector about medical reporting of death has begun, but the key challenge will be to ensure reliable reporting of HIV on death certificates. ${ }^{122,123}$

Two population-based surveys began in 2011, including the first South African Nutritional Health and Nutritional Examination Survey, which focused on nutrition, cardiovascular disease, and child health. ${ }^{64}$ The national HIV prevalence survey has been extended to include questions about maternal and child health. ${ }^{25}$ Without a clear

\begin{tabular}{|c|c|c|c|c|c|c|}
\hline & 2006 & 2007 & 2008 & 2009 & 2010 & 2011 \\
\hline $\begin{array}{l}\text { Individuals older than } 20 \text { years who received no } \\
\text { schooling }(\%)^{28}\end{array}$ & NA & $8 \cdot 7 \%$ & NA & $7 \cdot 4 \%$ & $7 \cdot 0 \%$ & NA \\
\hline Unemployment $(\%)^{109,110}$ & $25 \cdot 5 \%$ & $22 \cdot 7 \%$ & NA & $23 \cdot 6 \%$ & $25 \cdot 3 \%$ & $25.0 \%$ \\
\hline Individuals living in informal dwellings (\%) ${ }^{24}$ & NA & $15 \cdot 0 \%$ & NA & $13 \cdot 4 \%$ & $13 \cdot 0 \%$ & NA \\
\hline Drinking water performance rating $(\%)^{35 *}$ & NA & NA & NA & $51.4 \%$ & $67 \cdot 2 \%$ & $72 \cdot 9 \%$ \\
\hline Households with access to piped water (\%) & NA & NA & NA & $89 \cdot 3 \%$ & $89 \cdot 3 \%$ & NA \\
\hline Households that have no toilet facility $(\%)^{24}$ & NA & $7 \cdot 9 \%$ & NA & $6 \cdot 6 \%$ & $6 \cdot 1 \%$ & NA \\
\hline Households connected to the mains electricity supply $(\%)^{24}$ & NA & $81 \cdot 8 \%$ & NA & $82 \cdot 6 \%$ & $82 \cdot 0 \%$ & NA \\
\hline Medical scheme coverage $(\%)^{35}$ & NA & NA & $16 \cdot 0 \%$ & $16 \cdot 9 \%$ & $17 \cdot 6 \%$ & NA \\
\hline \multicolumn{7}{|c|}{$\begin{array}{l}\text { NA=not available. *Composite score measuring compliance of water suppliers with water quality management } \\
\text { requirements. }\end{array}$} \\
\hline
\end{tabular}

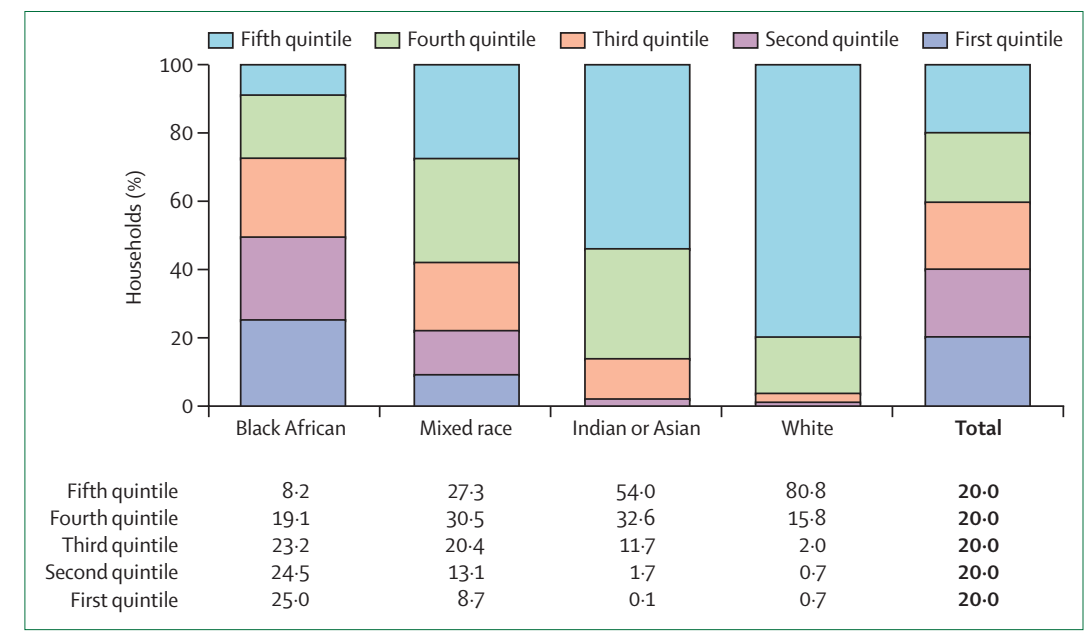

Figure 5: Distribution of households by household consumption expenditure in the four main population groups between September, 2008, and August, 2009

Quintiles based on household consumption expenditure including in-kind expenditure (ie, furnishing of services, property, or rights without charge or at a charge that is less than the fair market value) in 12 months. Population group designated according to reported ethnic group of head of household. First quintile=R16 406. Second quintile $=$ R26330. Third quintile $=R 43897$. Fourth quintile $=R 98053$. Fifth quintile $=>R 98053$. Reproduced from Statistics South Africa, ${ }^{111}$ by permission of Statistics South Africa.

monitoring and assessment framework defining the data necessary to monitor the health system, important population-based data might not be obtained.

Major investments have been made in the monitoring and assessment of the HIV/AIDS and tuberculosis programmes. ${ }^{120}$ The antenatal care survey, ${ }^{124}$ which is based on a random sample of pregnant women attending the health service, has provided a means to track HIV prevalence annually. This survey has been supplemented by household surveys and the recent South African pMTCT survey to track HIV transmission in a random sample of babies. ${ }^{42}$ Measurement of the incidence of HIV remains difficult and continues to be achieved through a modelling approach that is based on prevalence. ${ }^{119}$ Tuberculosis incidence is also challenging to assess, even though an electronic tuberculosis register is widely used for case notification, and modelling is necessary. ${ }^{116}$ Programmes for maternal, neonatal, and child health still do 
not have comprehensive data to allow the coverage of interventions known to improve child survival to be monitored. Information about exclusive breastfeeding and knowledge of oral rehydration solutions and other indicators are gathered from sporadic surveys. The NCD surveillance system still needs to be defined and set up, ${ }^{125}$ although a cancer register has been established on the basis of legislation. ${ }^{126}$ In the case of injuries, the surveillance of fatal injuries needs to be developed, as does that of non-fatal trauma, alcohol and substance misuse, and policy interventions.

The District Health Information System platform provides aggregate data from all primary-care facilities and district hospitals in the public sector. Established in about 2000, it has been strengthened since $2008^{127}$ and provides information for annual plans, the district health barometer, ${ }^{128}$ and the South African Health Review. ${ }^{120}$ Information about health-system function needs to be developed and coordinated further, partly because no standard medical record exists for the public sector and additionally because information is not consolidated between public and private sectors or academic hospitals. In the development of a strategic plan for human resources for health by the Department of Health, ${ }^{129}$ the scarcity of good-quality information about the health workforce also became apparent. Major problems with the plan are that it has not been costed and that the new cadres (such as clinical associates) meant to improve district hospitals that are important for maternal health have not been properly considered and no future plans for them envisaged. Health reform could easily founder because of the failure to solve this major problem. National health insurance brings an imperative to improve health information with diagnosisrelated groups, interventions, and pharmaceutical data.

As South Africa moves into a dynamic period of strengthening of health systems, with many initiatives attempting to deal with the quadruple burden of disease and improve health, a platform for assessment should be urgently considered, as proposed by Victora and colleagues. ${ }^{130}$ The district health barometer ${ }^{128}$ provides information for the 53 health districts in the country, but it will be important to supplement these data with information about different initiatives as they are implemented, and with division of the six metropolitan districts into subdistricts to understand the variations within the large cities. ${ }^{128}$ Strategic investment in the health information system is needed to develop the capacity to prepare, manage, and use data for decision making.

\section{Challenge 4: Scaling up of innovative interventions}

The 2009 Series called for increased innovation in service delivery and noted that HIV/AIDS interventions have tended to be more innovative than have others.? Innovations in maternal, neonatal, and child health were noted, such as quality-of-care mentor schemes, but few reached wide scale within a decade, apart from mortality audits. ${ }^{6}$ Initiation of national health insurance gives a potential platform for innovation at scale. ${ }^{95,131}$ A fundamental criticism of national health insurance, however, is that successful implementation will be constrained by the realities of poor administrative and managerial capacity of the state. ${ }^{13}$ Furthermore, capabilities of the civil service vary with province, ${ }^{91,132}$ making scale-up of innovations uneven and possibly even widening an equity gap unless targeting and incentives can lift the poorest-served provinces. Improved implementation of infrastructure, reorientation of health services towards compassionate care, efficient delivery of health services, and an improved understanding of how evidence informs policy and practice ${ }^{133}$ underpin scaling up of interventions for all four epidemics.

\section{Conclusion}

We have summarised the important changes in South Africa's health dialogue and care of its people. A determined leadership for health has contributed to major successes in the confrontation and management of some of the most serious epidemics affecting modern societies: HIV/AIDS; tuberculosis; high mortality of women and young children and their mothers; a nascent and rising threat of NCDs; and unconscionable effects of relentless and pervasive violence. In the past few years, the inexorable mortality increases have reached a peak and started to decrease, ${ }^{33}$ moving on from the grave historical distortions of colonial and apartheid governments, as well as the era of Mbeki and his notorious Minister of Health Mantombazana Tshabalala-Msimang. Undeniably, much remains to be done to improve the health and living conditions of large sections of the population. However, for the first time in two decades, this progress instils a basis for hope. The radical transformation of the health system through national health insurance holds potential for universal access to effective programmes to promote health, prevent disease, care for the sick, and support the disabled. Development of an effective human resource system with data for action could still place South Africa on track for MDGs 4, 5, and 6. Efforts to address the challenges and answer the 2009 call for action need to be redoubled. ${ }^{10}$ Implementation of these recommendations depends on the effectiveness of the government and the demand by citizens to access their basic rights and entitlements and discharge their responsibilities. It might be reasonable to expect that the most pressing concerns for the health of the people will be realised by a political party which through a century of struggle ensured the citizenship, dignity and pride of all South Africans, both black and white.

\section{Contributors}

The paper outline was developed by BMM, JEL, and HMC, and was refined by all authors. SSAK drafted the section about HIV and tuberculosis; JEL the section about maternal, neonatal, and child health; $\mathrm{BMM}$ and DB the section about non-communicable diseases and mental health; and AvN the section about violence and injuries. BMM drafted the section about consensus about health research; and DB the sections about social determinants and racial disparities, integration and 
coordination, and surveillance and information. JEL drafted the Summary and the section about scaling up of innovative interventions. HMC drafted the Introduction, the Conclusion, and the sections about leadership as a key driver and universal coverage with national health insurance. All the authors reviewed and refined the report.

\section{The Lancet South Africa team}

Q Abdool Karim, S S Abdool Karim, P Barron, D Bradshaw, M Chopra, G J Churchyard, H M Coovadia, R Jewkes, U G Lalloo, J E Lawn, S D Lawn, B M Mayosi, R Pattinson, M Seedat, F Sitas, S Suffla, S M Tollman, and A Van Niekerk.

\section{Conflicts of interest}

We declare that we have no conflicts of interest.

\section{Acknowledgments}

Bongani Mayosi is partly funded by the Lily and Hausmann Research Trust, the South African Medical Research Council, and the National Research Foundation of South Africa. We thank Kate Kerber for help with data for figure 1 and Ria Laubscher for assisting with data for figures 1 and 3 .

\section{References}

1 Kleinert S, Horton R. South Africa's health: departing for a better future? Lancet 2009; 374: 759-60.

2 Gevisser M. Thabo Mbeki: the dream deferred. Cape Town: Jonathan Ball Publishers, 2007.

3 Coovadia H, Coovadia I. Science and society: the HIV epidemic and South African political responses. In: Finn A, Pollard AJ, eds. Hot topics in infection and immunity in children IV. New York, NY: Springer, 2008: 16-28.

4 Makgoba MW. HIV/AIDS: the peril of pseudoscience. Science 2000; 288: 1171.

5 Coovadia H, Jewkes R, Barron P, Sanders D, McIntyre D. The health and health system of South Africa: historical roots of current public health challenges. Lancet 2009; 374: 817-34.

6 Chopra M, Daviaud E, Pattinson R, Fonn S, Lawn JE. Saving the lives of South Africa's mothers, babies, and children: can the health system deliver? Lancet 2009; 374: 835-46.

7 Abdool Karim SS, Churchyard GJ, Abdool Karim Q, Lawn SD. HIV infection and tuberculosis in South Africa: an urgent need to escalate the public health response. Lancet 2009; 374: 921-33.

8 Mayosi BM, Flisher AJ, Lalloo UG, Sitas F, Tollman SM, Bradshaw D. The burden of non-communicable diseases in South Africa. Lancet 2009; 374: 934-47.

9 Seedat M, Van Niekerk A, Jewkes R, Suffla S, Ratele K. Violence and injuries in South Africa: prioritising an agenda for prevention. Lancet 2009; 374: 1011-22.

10 Chopra M, Lawn JE, Sanders D, et al. Achieving the health Millennium Development Goals for South Africa: challenges and priorities. Lancet 2009; 374: 1023-31.

11 South African Government. Address by the Minister of Health, Dr Aaron Motsoaledi at the media launch of the Lancet Country Series on Health in South Africa. Aug 24, 2009. http://www.info. gov.za/speeches/2009/09082613551001.htm (accessed Nov 9, 2012).

12 Mail and Guardian Online. Motsoaledi: more must be done to reduce child deaths. Aug 25, 2009. http://mg.co.za/ article/2009-08-25-motsoaledi-more-must-be-done-to-reduce-childdeaths (accessed Nov 9, 2012).

13 National Planning Commission. Diagnostic overview. 2011 http://www.npconline.co.za/MediaLib/Downloads/Home/Tabs/ Diagnostic/Diagnostic\%20Overview.pdf (accessed Nov 9, 2012).

14 The Lancet. South Africa's AIDS response: the next 5 years. Lancet 2012; 379: 1365.

15 Gilson L, Daire J. Leadership and governance within the South African health system. In: Padarath A, English R, eds. South African health review 2011. Durban: Health Systems Trust, 2011: 69-80.

16 Schaay N, Sanders D, Lehmann U. Health service management training. In: Ntuli A, ed. South African health review 1998. Durban: Health Systems Trust, 1998: 93-102.

17 Doherty J, Gilson L. South African health managers speak out: lessons for innovative health management in the public sector. Cape Town: University of Cape Town, 2011

18 Kahn K. Population health in South Africa: dynamics over the past two decades. J Public Health Policy 2011; 32: S30-36.
19 Tollman SM, Kahn K, Sartorius B, Collinson MA, Clark SJ, Garenne ML. Implications of mortality transition for primary health care in rural South Africa: a population-based surveillance study. Lancet 2008; 372: 893-901.

20 Department of Health. Annual Report 2010/11. Sept 26, 2011. http:// www.doh.gov.za/docs/reports/annual/2011/annual_report2010-11. pdf (accessed Nov 9, 2012).

21 Amnesty International USA. Hidden from view: HIV and women in rural South Africa. http://www.amnestyusa.org/our-work/ countries/africa/south-africa/hidden-from-view-hiv-and-women-inrural-south-africa (accessed Aug 11, 2012).

22 South African Government. Outline of the national HIV Counselling and Testing (HCT) campaign by Dr Aaron Motsoaledi, Minister of Health. March 25, 2010. http://www.info.gov.za/ speeches/2010/10032611051001.htm (accessed Aug 11, 2012).

23 South African National AIDS Council. National strategic plan on HIV, STIs and TB: 2012-2016. 2011. http://www.doh.gov.za/docs/ stratdocs/2012/NSPfull.pdf (accessed Nov 9, 2012).

24 Statistics South Africa. Mid-year population estimates, 2011. http:// www.statssa.gov.za/publications/statsdownload. asp?PPN=p0302\&SCH=4986 (accessed Nov 10, 2012)

25 Shisana O, Rehle T, Simbayi LC, et al. South African national HIV prevalence, incidence, behaviour and communication survey, 2008: a turning tide among teenagers? Cape Town: HSRC Press, 2009.

26 Department of Health. Annual Report 2006/07. Pretoria: National Department of Health, 2007.

27 WHO. Progress report 2011:- global HIV/AIDS response: epidemic update and health sector progress towards Universal Access. http://www.who.int/hiv/pub/progress_report2011/en/ index.html (accessed March 12, 2012).

28 Johnson L. Access to antiretroviral treatment in South Africa, 2004-2011. South Afr J HIV Med 2012; 13: 22-27.

29 Adam MA, Johnson LF. Estimation of adult antiretroviral treatment coverage in South Africa. S Afr Med J 2009; 99: 661-67.

30 WHO. South Africa: tuberculosis profile. 2011. https://extranet.who. int/sree/Reports?op=Replet\&name=\%2FWHO_HQ Reports\%2FG 2\%2FPROD\%2FEXT\%2FTBCountryProfile\&ISO2=ZA\&LAN= EN\&outtype $=$ html (accessed Nov 9, 2012).

31 WHO. Global tuberculosis control 2011. 2011. http://www.who.int/ tb/publications/global_report/2011/gtbr11_full.pdf (accessed March 12, 2012).

32 Auvert B, Taljaard D, Rech D, et al. Effect of the roll-out (ANRS-12126) of male circumcision in Orange Farm (South Africa) on the spread of HIV. Sixth International AIDS Society Conference on HIV Pathogenesis, Treatment and Prevention; Rome; July 17-20, 2011. WELBC02.

33 Bradshaw D, Dorrington RE, Laubscher R. Rapid mortality surveillance report 2011. Cape Town: South African Medical Research Council, 2012

34 Department of Health. Malaria Elimination Monitoring and Evaluation Plan 2012-2018. Pretoria: Department of Health, 2012.

35 Day C, Gray A, Budgell E. Health and related indicators: South African health review 2011. Durban: Health Systems Trust, 2012.

36 National Health Laboratory Service. Xpert MTB/RIF for diagnosis of tuberculosis: evaluating impact and cost-effectiveness in the routine roll-out in South Africa. 2012. http://www.nhls.ac.za/ ?page=xtend_study\&id=78 (accessed Aug 11, 2012).

37 Department of Health. HIV and AIDS and STI Strategic Plan for South Africa, 2007-2011. March 14, 2007. http://www.doh.gov.za/ docs/strategicplan/2007/part1.pdf (accessed March 30, 2012).

38 WHO. Antiretroviral drugs for treating pregnant women and preventing HIV infection in infants: towards universal accessrecommendations for a public health approach. 2006. http://www. who.int/hiv/pub/mtct/pmtct/en/ (accessed Aug 2, 2012).

39 Chweneyagae D, Delis-Jarrosay N, Farina Z, et al. The impact of HIV infection on maternal deaths in South Africa. S Afr J Obstet Gynaecol 2012; 18: 70-76.

40 UNAIDS Report on the global AIDS Epidemic 2010. http://www. unaids.org/globalreport/Global_report.htm (accessed July 17, 2012).

41 WHO, UNICEF. Countdown to 2015: Maternal, Newborn and Child Survival-building a future for women and children, the 2012 Report. 2012. http://www.countdown2015mnch.org/ documents /2012Report/2012-complete-no-profiles.pdf (accessed Nov 9, 2012) 
42 Goga A, Dinh T-H, Jackson D, for the SAPMTCTE study group. Evaluation of the effectiveness of the national prevention of mother-to-child transmission (PMTCT) programme on infant HIV measured at six weeks postpartum in South Africa, 2010. 2012. http://www.doh.gov.za/docs/reports/2012/pmtcteffectiveness.pdf (accessed Nov 9, 2012).

43 Becquet R, Bland R, Leroy V, et al. Duration, pattern of breastfeeding and postnatal transmission of HIV: pooled analysis of individual data from west and South African cohorts. PLoS One 2009; 4: e7397.

44 South African Government. Launch of the campaign accelarated reduction of maternal mortality in Africa (CARMMA) in South Africa, KwaZulu-Natal. May 2, 2012. http://www.info.gov.za/ speech/DynamicAction?pageid=461\&sid=27013\&tid=66231 (accessed Aug 11, 2012).

45 Department of Health. Saving mothers 2008-2010: fifth report on the confidential enquiries into maternal deaths in South Africashort report. 2012. http://www.doh.gov.za/docs/reports/2012/ savingmothersshort.pdf (accessed Nov 9, 2012).

46 National Perinatal Mortality and Morbidity Committee. National Perinatal Mortality and Morbidity Committee (NaPeMMCo) triennial report (2008-2010). June, 2011. http://www.doh.gov.za/ docs/reports/2011/perireport.pdf (accessed Nov 9, 2012).

47 Department of Health. First Tiennial Report of the Committee on Morbidity and Mortality in Children Under 5 Years (CoMMiC). 2011. http://www.doh.gov.za/docs/reports/2011/morbreport.pdf (accessed Nov 9, 2012).

48 Kerber K, Tuaone-Nkhasi M, Dorrington RE, et al. Progress towards Millennium Development Goal 4. Lancet 2012; 379: 1193.

49 Creswell J, Raviglione M, Ottmani S, et al. Tuberculosis and noncommunicable diseases: neglected links and missed opportunities. Eur Respir J 2011; 37: 1269-82.

50 Levitt NS, Steyn K, Dave J, Bradshaw D. Chronic noncommunicable diseases and HIV-AIDS on a collision course: relevance for health care delivery, particularly in low-resource settings-insights from South Africa. Am J Clin Nutr 2011; 94: S1690-96.

51 Peer N, Bradshaw D, Laubscher R, Steyn K. Trends in adult tobacco use from two South African Demographic and Health Surveys conducted in 1998 and 2003. S Afr Med J 2009; 99: 744-49.

52 Ntusi NB. Dismal management of hypertension at primary level: does it reflect a failure of patients, a failure of the system or a failure of doctors? Cardiovasc J Afr 2011; 22: 172-74.

53 Beaglehole R, Bonita R, Alleyne G, et al. UN High-Level Meeting on Non-Communicable Diseases: addressing four questions. Lancet 2011; 378: 449-55.

54 Department of Health. South African Declaration on the Prevention and Control of Non-Communicable Diseases. Pretoria, 2011.

55 Bertram MY, Steyn K, Wentzel-Viljoen E, Tollman S, Hofman KJ. Reducing the sodium content of high-salt foods: effect on cardiovascular disease in South Africa. S Afr Med J 2012; 102: 743-45.

56 Hartley W. Motsoaledi takes aim at alcohol adverts, smoking. Feb 20 , 2012. http://www.bdlive.co.za/articles/2012/02/20/motsoaledi-takesaim-at-alcohol-adverts-smoking (accessed Nov 9, 2012).

57 Coltart C, Anderson I, Barh B, et al. An international consensus for medical leadership on alcohol. Lancet 2011; 378: 1215

58 Chersich MF, Rees HV. Causal links between binge drinking patterns, unsafe sex and HIV in South Africa: its time to intervene. Int J STD AIDS 2010; 21: 2-7.

59 Esterhuizen TM, Hnizdo E, Rees D, et al. Occupational respiratory diseases in South Africa-results from SORDSA, 1997-1999. S Afr Med J 2001; 91: 502-08.

60 WHO. Global strategy to reduce harmful use of alcohol. Geneva: World Health Organization, 2010

61 Petersen I, Lund C. Mental health service delivery in South Africa from 2000 to 2010: one step forward, one step back. S Afr Med J 2011; 101: 751-57.

62 Sorsdahl K, Stein DJ, Lund C. Mental health services in South Africa: scaling up and future directions. Afr J Psychiatry (Johannesbg) 2012; 15: 168-71.

63 Statistics South Africa. Mortality and causes of death in South Africa, 2009: findings from death notification. Nov 30, 2011. http:// www.statssa.gov.za/publications/P03093/P030932009.pdf (accessed Dec 2, 2011).
64 Human Sciences Research Council. The South African National Health and Nutrition Examination Survey, 2011/2012. 2012. http://www.hsrc.ac.za/Document-4377.phtml (accessed Nov 9, 2012).

65 Norman R, Matzopoulos R, Groenewald P, Bradshaw D. The high burden of injuries in South Africa. Bull World Health Organ 2007; 85: 695-702.

66 South African Police Service. Crime Report 2010/2011. 2011. http://www.info.gov.za/view/DownloadFileAction?id=150105 (accessed Nov 9, 2012)

67 Road Traffic Management Corporation. Annual Report 2010/2011. 2011. http://www.rtmc.co.za/RTMC/Files/RTMC\%20AR/ RTMC\%20AR\%202010\%20-\%202011.pdf (accessed Nov 9, 2012).

68 Safety and Peace Promotion Research Unit. A profile of fatal injuries in Gauteng 2010: annual report for Gauteng based on the National Injury Mortality Surveillance System (NIMSS). May, 2012. http://www.mrc.ac.za/crime/NIMSSGauteng2010.pdf (accessed Nov 9, 2012).

69 Safety and Peace Promotion Research Unit. A profile of fatal injuries in Mpumalanga 2010: annual report for Mpumalanga based on the National Injury Mortality Surveillance System (NIMSS). May, 2012. http://www.mrc.ac.za/crime/NIMSSMpumalanga2010.pdf (accessed Nov 9, 2012).

70 Bornman S, Budlender D, Vetton L, Van der Westhuizen C, Watson J, Williams J. The state of the nation, government priorities and women in South Africa. Cape Town: Women's Legal Centre, 2012.

71 Altbeker A. Murder and robbery in South Africa: a tale of two trends. In: Van Niekerk A, Suffla S, Seedat M, eds. Crime, violence and injury prevention in South Africa: data to action. Tygerberg: MRC-UNISA Crime, Violence and Injury Lead Programme, 2008: 122-49.

72 Ward CL, Artz L, Berg J, et al. Violence, violence prevention, and safety: a research agenda for South Africa. S Afr Med J 2012 102: 215-18.

73 Jewkes R, Nduna M, Levin J, et al. Impact of stepping stones on incidence of HIV and HSV-2 and sexual behaviour in rural South Africa: cluster randomised controlled trial. BMJ 2008; 337: a506.

74 Jewkes R, Sikweyiya Y, Morrell R, Dunkle K. Gender inequitable masculinity and sexual entitlement in rape perpetration South Africa: findings of a cross-sectional study. PLoS One 2011; 6: e29590.

75 Jewkes R, Sikweyiya Y, Morrell R, Dunkle K. Understanding men's health and use of violence: interface of rape and HIV in South Africa. June, 2009. http://www.mrc.ac.za/gender/violence_hiv.pdf (accessed Nov 9, 2012).

76 Ratele K, Smith M, Van Niekerk A, Seedat M. Is it race, age or sex? Masculinity in male homicide victimisation in urban South Africa. In: Gould C, ed. National and international perspectives on crime and policing. Pretoria: Institute for Security Studies, 2011: 44-58.

77 van Niekerk A, Suffla S, Seedat M, eds. Crime, violence and injury in South Africa: 21st century solutions for child safety. Cape Town: Psychological Association of South Africa, 2012.

78 Sukhai A, Jones AP, Love BS, Haynes R. Temporal variations in road traffic fatalities in South Africa. Accident Anal Prev 2011; 43: 421-28.

79 Sukhai A, Jones AP, Love BS, Haynes R. Temporal variations in road traffic fatalities in South Africa. Accid Anal Prev 2011; 43: 421-28.

80 Department of Social Development. Statement by the Department of Social Development on the resolution of the Second Biennial Substance Abuse Summit. March 17, 2012. http://www.polity.org. za/article/sa-statement-by-the-department-of-social-developmenton-the-resolution-of-the-second-biennial-substance-abusesummit-17032011-2011-03-17 (accessed Nov 9, 2012).

81 Abrahams N, Jewkes R, Martin LJ, Mathews S, Vetten L, Lombard C. Mortality of women from intimate partner violence in South Africa: a national epidemiological study. Violence Vict 2009; 24: 546-56.

82 GunFree South Africa. 8000 missing firearms. March 19, 2009. http://www.gunfree.org.za/Home/tabid/1120/ctl/Details/ mid/8022/ItemID/468/language/en-US/Default.aspx (accessed Nov 9, 2012).

83 Institute for Security Studies. Submission by the Institute for Security Studies to the Parliamentary Portfolio Committee on Justice and Constitutional Development: the Criminal Procedure Amendment Bill [B39- 2010]. July 29, 2011. http://www.issafrica. org/crimehub/uploads/ISS_CPA_Amendment_Bill_ Submission_29_July_2011.pdf (accessed Nov 9, 2012). 
84 Newham G. Arresting a few policemen will not solve South Africa's violent policing problem. 2011. http://www.polity.org.za/article/ arresting-a-few-policemen-will-not-solve-south-africas-violentpolicing-problem-2011-04-19 (accessed Oct 5, 2012).

85 Independent Complaints Directorate. Annual report 2010-2011. Pretoria: Independent Complaints Directorate, 2011.

86 Krug EG, Dahlberg LL, Mercy JA, Zwi AB, Lozano R, eds. World report on violence and health. Geneva: World Health Organization, 2002.

87 Krug EG, Mercy JA, Dahlberg LL, Zwi AB. The world report on violence and health. Lancet 2002; 360: 1083-88.

88 Phillips HT. The 1945 Gluckman Report and the establishment of South Africa's health centers. Am J Public Health 1993; 83: 1037-39.

89 World Health Assembly. Sustainable health financing structures and universal coverage: 64th World Health Assembly agenda item 13.4. May 24, 2011. http://apps.who.int/gb/ebwha/pdf_files/ WHA64/A64_R9-en.pdf (accessed July 18, 2012).

90 Department of Health. National Health Insurance in South Africa: policy paper. Aug 12, 2011. http://www.greengazette.co.za/notices/ national-health-act-no-61-of-2003-policy-on-national-health-insurancedraft_20110812-GGN-34523-00657 (accessed Nov 9, 2012).

91 Mills A, Ataguba JE, Akazili J, et al. Equity in financing and use of health care in Ghana, South Africa, and Tanzania: implications for paths to universal coverage. Lancet 2012; 380: 126-33.

92 Harris B, Goudge J, Ataguba JE, et al. Inequities in access to health care in South Africa. J Public Health Pol 2011; 32 (suppl 1): S102-23.

93 Council for Medical Schemes. Annual Report, 2008-09. Pretoria: Council for Medical Schemes, 2009.

94 KPMG. Funding NHI: a spoonful of sugar? An economic analysis of the NHI. 2011. http://www.kpmg.com/ZA/en/IssuesAndInsights/ ArticlesPublications/General-Industries-Publications/Documents/ KPMG\%20NHI\%20Economic\%20Impact\%20Research\%20 brochure.pdf (accessed Nov 9, 2012).

95 Shisana O. NHI consensus: fix the existing system or risk failure. S Afr Med J 2010; 100: 791-93.

96 van den Heever A. Evaluation of the green paper on national health insurance. Dec 20, 2011. http://www.hsf.org.za/siteworkspace/ gp-review-alexvdh-dec2011-vf-1.pdf (accessed Nov 9, 2012).

97 Republic of South Africa. 2012 budget speech: Minister of Finance Pravin Gordhan. Feb 22, 2012. http://www.treasury.gov.za/documents/ national\%20budget/2012/speech/speech.pdf (accessed July 18, 2012).

98 health-e. NHI pilot district profiles. 2012. http://www.health-e.org za/news/article.php?uid=20033505 (accessed Nov 9, 2012).

99 Gevers W. Clinical research in South Africa: a core asset under pressure. Lancet 2009; 374: 760-62.

100 Mayosi BM, Dhai A, Folb P, et al. Consensus report on revitalising clinical research: a study on clinical research and related training in South Africa. Pretoria: Academy of Science of South Africa, 2009.

101 The SARRAH Programme. The South African health improvement plan. 2009. http://www.sarrahsouthafrica.org/LinkClick.aspx? fileticket=_cJ12FdD4-g\%3D\&tabid=2067 (accessed July 29, 2012).

102 Mayosi BM, Mekwa JN, Blackburn J, et al. Strengthening research for health, innovation and development in South Africa: proceedings and recommendations of the 2011 National Health Research Summit. Pretoria: National Health Research Committee, 2012.

103 The Lancet. The Bamako call to action: research for health. Lancet 2008; 372: 1855.

104 Bateman C. Academic health complexes bleeding in 'no man's land'. S Afr Med J 2010; 100: 17-19.

105 Nordling L. South Africa invests in research training. April 26, 2012. http://blogs.nature.com/news/2012/04/south-africa-invests-inhealth-research-training.html (accessed July 29, 2012).

106 South African Journal of Science. Purposeful support for health research in South Africa. S Afr J Sci 2012; 108: 1.

107 Marmot M. Social determinants of health inequalities. Lancet 2005; 365: 1099-104.

108 Victora CG, Barreto ML, do Carmo Leal M, et al. Health conditions and health-policy innovations in Brazil: the way forward. Lancet 2011; 377: 2042-53.

109 Statistics South Africa. Statistical release P0210: labour force survey-historical revision September series, 2000-2007. March 23, 2009. http://www.statssa.gov.za/publications/P0210/ P0210September2000,2001,2002,2003,2004,2005,2006,2007.pdf (accessed Nov 9, 2012).
110 Statistics South Africa. Statistical release P0211: quarterly labour force survey-quarter 3, 2011. Nov 1, 2011. http://www.statssa.gov.za/ publications/P0211/P02113rdQuarter2011.pdf (accessed Aug 2, 2012).

111 Statistics South Africa. Living conditions of households in SA 2008/2009. Pretoria: Statistics South Africa, 2011.

112 Republic of South Africa. Human conditions diagnostic. 2011. http:// www.npconline.co.za/MediaLib/Downloads/Home/Tabs/Diagnostic/ Diagnostic_Human_conditions.pdf (accessed July 18, 2012).

113 Abdool Karim SS, Naidoo K, Grobler A, et al. Timing of initiation of antiretroviral drugs during tuberculosis therapy. N Engl J Med 2010; 362: 697-706.

114 Abdool Karim SS, Naidoo K, Grobler A, et al. Integration of antiretroviral therapy with tuberculosis treatment. $N \mathrm{Engl} \mathrm{J} \mathrm{Med}$ 2011; 365: 1492-501.

115 Havlir DV, Kendall MA, Ive P, et al. Timing of antiretroviral therapy for HIV-1 infection and tuberculosis. N Eng J Med 2011; 365: 1482-91.

116 WHO. Global tuberculosis report 2012. www.who.int/tb/ publications/global_report/ (accessed Nov 9, 2012).

117 Republic of South Africa. Country progress report on the declaration of commitment on HIV/AIDS: 2010 report. March 31, 2010. http://data.unaids.org/pub/report/2010/southafrica_2010_ country_progress_report_en.pdf (accessed Nov 9, 2012).

118 South African Government. The outcomes approach. Oct 25, 2010. http://www.info.gov.za/issues/outcomes/index.html (accessed Nov 9, 2012).

119 Health Data Advisory Committee. Health Data Advisory Committee (HDACC) Report. Pretoria: Department of Health, 2012.

120 English R, Masilela T, Barron P, Schönfeldt A. Health information in South Africa. In: Padarath A, English R, eds. South African Health Review 2011. Durban: Health Systems Trust, 2012: 81-89.

121 Pillay-van Wyk V, Bradshaw D, Groenewald P, Laubscher R. Improving the quality of medical certification of cause of death: the time is now! S Afr Med J 2011; 101: 626.

122 Yudkin PL, Burger EH, Bradshaw D, Groenewald P, Ward AM, Volmink J. Deaths caused by HIV disease under-reported in South Africa. AIDS 2009; 23: 1600-02.

123 Burger EH, Groenewald P, Bradshaw D, Ward AM, Yudkin PL Volmink J. Validation study of cause of death statistics in Cape Town, South Africa, found poor agreement. J Clin Epidemiol 2012; 65: 309-16.

124 Department of Health. The 2010 national antenatal sentinel HIV and syphilis prevalence survey in South Africa. 2011. http://www.info.gov. za/view/DownloadFileAction?id=155559 (accessed Nov 9, 2012).

125 Bradshaw D, Steyn K, Kengne A-P. Surveillance and research for the prevention and control of NCDs. http://www.doh.gov.za/docs/ misc/2011/surveillance_and_research.pdf (accessed July 18, 2012).

126 Singh E. New regulations on cancer notification in South Africa. Nov 15, 2011. http://www.phasa.org.za/articles/new-regulations-oncancer-notification-in-south-africa.html (accessed Aug 11, 2012).

127 Health Systems Trust. Project: health information system for data capturers (HISDC). 2011. http://new.hst.org.za/content/ project-health-information-system-data-capturers-hisdc (accessed Nov 10, 2012).

128 Health Systems Trust. District health barometer. http://www.hst. org.za/district-health-barometer-dhb-2 (accessed July 29, 2012).

129 Department of Health. HRH strategy for the health sector 2012/13-2016/17. Pretoria: Department of Health, 2012.

130 Victora CG, Black RE, Boerma JT, Bryce J. Measuring impact in the Millennium Development Goal era and beyond: a new approach to large-scale effectiveness evaluations. Lancet 2011; 377: 85-95.

131 Pillay Y, White C, McCormick N. How times have changed: HIV and AIDS in South Africa in 2011. S Afr Med J 2012; 102: 77-78.

132 National Planning Commission. Building a capable state: National Development Plan Vision for 2030. Pretoria: Republic of South Africa, 2011.

133 Bowen S, Zwi AB. Pathways to "evidence-informed" policy and practice: a framework for action. PLoS Med 2005; 2: e166. 